\title{
Ultrasound and Modern Regional Anaesthesia
}

\author{
T.V.S. Gopal ${ }^{1,2,3}$ \\ ${ }^{1}$ Managing Director, Axon Anaesthesia Associates, Hyderabad, Telangana, India. \\ ${ }^{2}$ Clinical Director, Anaesthesiology, General O.T.\& C.O.P.Complex, Care Hospitals, Hyderabad, Telangana, India. \\ ${ }^{3}$ Chairperson, Past Academic Director \& President AORA India.
}

Lazzaro Spallanzani, an $18^{\text {th }}$ century Italian biologist, is credited with the discovery of ultrasound, which he coined 'echolocation'. [1] Little may he have realized then that his revelation would transform into an all pervading technology in modern science. Though La Grange and colleagues, in 1978, were the first to employ ultrasonic blood flow detector to locate insertion point for the supraclavicular brachial plexus block, ultrasound guidance in real time motion was first utilized by S. Kapral et al for the same block in a series of forty patients in 1994, thus, heralding a fresh epoch in regional anaesthesia. [2,3] As is often the case with the introduction of new technologies, ultrasound guidance was also met with cynicism and disdainful resistance. However, not much later, ultrasound guidance was being hailed as the 'gold standard' for regional anaesthesia, and it was proclaimed that the search for the elusive 'holy grail'had ended. [4]

Among the first nerve/plexus blocks to find wider acceptance with the adoption of ultrasound guidance was the supraclavicular brachial plexus block. The fear of arterial puncture and accidental pneumothorax magically seemed to vanish into thin air. Correlation between clinical and sono-anatomy led to a better understanding of interscalene, infraclavicular and axillary approaches to the brachial plexus. [5] Lower limb blocks began to witness a renaissance due to the widespread prescription of antiplatelet drugs as part of preventive cardiology. Though deeper to the skin in comparison to the upper limb, ultrasound guidance improved identification of neural structures.

It was reported in literature that ultrasound improves patient comfort, block acceptance, onset of block, quality of block, permits the injection of lower local anaesthetic volumes, and thereby, the potential for LAST, and reduces the incidence of certain complications that may be attributed to the block procedure. [6] However, given the resolution of current portable ultrasound machines, and the huge numbers required to reflect a statistical difference in favour of ultrasound, the rate of neurological complications seems to be comparable to other guidance techniques. Such are the rigours of evidence-based medicine!!

Familiarity with ultrasound offered precision with blocks of the brachial plexus, for eg., intertruncal blockade, combination of superior truncal and cervical plexus block (SCUT), costoclavicular approach to the infraclavicular plexus, and identification of inadvertent targets "in the path", namely, the long thoracic and dorsal scapular nerves. [7, 8] Not surprisingly, ultrasound guidance was utilized for deeper blocks such as lumbar and sacral plexus, giving impetus to the term, "dual guidance" technique. A "window of opportunity" led to description of neuraxial sonoanatomy and the various benefits of ultrasound assistance for neuraxial blocks were widely appreciated. [9] Nearly seven decades after Mario Dogliotti invented the loss of resistance technique for identification of the epidural space, another guidance tool was incorporated. Newer approaches to older blocks were introduced, such as the suprainguinal fascia iliaca plane block. Differential blocks limited to sensory desensitization alone came into vogue, viz.PENG (Pericapsular Nerve Group), iliopsoas plane block \& the i-PACK. [10, 11]

\author{
Address of Correspondence: \\ Dr. T.V.S Gopal, \\ Managing Director, Axon Anaesthesia Associates, Hyderabad, Telangana, India. \\ Clinical Director, Anaesthesiology, General O.T.\& C.O.P.Complex, Care Hospitals, Hyderabad, Telangana, India. \\ E-mail: tvsgopal@gmail.com
}

DOI: $10.13107 /$ ijra.2021.v02i02.035 | www.ijrajournal.com |

This is an Open Access article distributed under the terms of the Creative Commons Attribution Non-Commercial-Share Alike 4.0 License

(http://creativecommons.org/licenses/by-nc-sa/4.0) which allows others to remix, tweak, and build upon the work non-commercially as long as appropriate credit is given and the new creation are licensed under the identical terms. 
Perhaps, the most significant shift in regional anaesthesia was the introduction of interfascial plane blocks that abandoned the "search" for neural structures by beckoning regional anaesthesia enthusiasts to deposit large volumes of local anaesthetic solutions into fascial planes. What began with the ultrasound guided TAP block in 2007, rapidly found application in a variety of truncal fascial planes. The interfascial plane block added a new dimension to the multimodal analgesia regime. Simplicity of performance and safety was the overriding factor that appealed to anaesthesiologists. With some blocks, the drug was confined to the point of injection. With several others, the propensity of aponeurotic fascia to communicate with other fascial planes facilitated the theoretical spread of drug to sites far removed from the point of injection. Though conjecture exists with respect to the mechanism of action of blocks such as the QLB, future studies should put an end to controversies. [12]

The erector spinae block, first published by Forero et al, in 2016, set the world of regional anaesthesia literally on fire. [13] In the past five years, several publications, mostly case reports and limited case series, eulogizing the virtues of, the potential for, the clinical applications for, and the possible mechanism of action of this popular block, have emerged in scientific literature. [14] Currently, this ESP block, due to a lack of credible evidence on the mechanism of action, has the naysayers clamouring for this block to be rested in peace. [15] Given that the ESP has been in existence for less than five years, it is sincerely hoped that concrete studies may demystify this esoteric block.

In addition to regional anaesthesia, the appeal of modern, portable ultrasound places the FOCUS firmly on POCUS or Point Of Care Ultrasound. Today, regional anaesthesiologists are comfortable with fancy acronyms like FATE, FEEL, FAST etc. The integration of Artifical Intelligence to ultrasound technology imparts further precision. High resolution ultrasound as a diagnostic and therapeutic tool with multiple applications for clinicians is here to stay. The chorus for fusion of ultrasound into clinical practice is based on the edifice of evidence, ubiquity and durability, and NOT on the caprice of an elite core of die-hard proponents. The sooner anaesthesiologists jump on the bandwagon and hitch a ride, the better.

It is my sacred duty, as Chairperson of AORA INDIA, to place on record my appreciation to the editorial board of the International Journal of Regional Anaesthesia for embarking on this challenging journey of enlightening readers with advances in the exciting field of regional anaesthesia. In years to come, this online, peer reviewed journal will hopefully have made entry into the pantheon of impactful regional anaesthesia journals worldwide. Indeed, as the famous quote goes, "the purpose of education is to turn mirrors into windows".

T.V.S. Gopal

Chairperson, Past Academic Director \& President

Conflict of interest: Nil Source of support: None

\section{References}

1. Kaproth-Joslin KA, Nicola R, Dogra VS. The History of US: From Bats and Boats to the Bedside and Beyond: RSNA Centennial Article. Radiographics. 2015; 35:960-70.

2. la Grange P, Foster PA, Pretorius LK. Application of the Doppler ultrasound bloodflow detector in supraclavicular brachial plexus block. BrJ Anaesth. 1978; 50:965-7.

3. Kapral S, Krafft P, Eibenberger K, Fitzgerald R, Gosch M, Weinstabl C. Ultrasoundguided supraclavicular approach for regional anesthesia of the brachial plexus. Anesth Analg. 1994; 78:507-13.

4. Horlocker TT, Wedel DJ. Ultrasound-guided regional anesthesia: in search of the holy grail. Anesth Analg 2007; 104:1009-11.

5. Sites BD, Spence BC, Gallagher J, Beach ML, Antonakakis JG, Sites VR, Hartman GS. Regional anesthesia meets ultrasound: a specialty in transition. Acta Anaesthesiol Scand. 2008; 52:456-66.

6. Neal JM. Ultrasound-Guided Regional Anesthesia and Patient Safety: Update of an Evidence-Based Analysis. Reg Anesth Pain Med. 2016; 41:195-204.

7. Karmakar MK, Pakpirom J, Songthamwat B, Areeruk P. High definition ultrasound imaging of the individual elements of the brachial plexus above the clavicle. Reg Anesth Pain Med.2020; 45:344-50.

8. Hanson NA, Auyong DB. Systematic ultrasound identification of the dorsal scapular and long thoracic nerves during interscalene block. Reg Anesth Pain Med. 2013; $38: 54$

$---$
7.

9. Kalagara, H., Nair, H., Kolli, S. et al. Ultrasound Imaging of the Spine for Central Neuraxial Blockade: a Technical Description and Evidence Update. Curr Anesthesiol Rep.2021; 11:326-39.

10. Bugada D, Bellini V, Lorini LF, Mariano ER. Update on Selective Regional Analgesia for Hip Surgery Patients. Anesthesiol Clin. 2018; 36:403-15..

11. Tran J, Giron Arango L, Peng P, Sinha SK, Agur A, Chan V. Evaluation of the iPACK block injectate spread: a cadaveric study. Reg Anesth Pain Med. 2019: rapm-2018100355.

12. Gopal TVS, Maniar A, Chakraborty A, Kulkarni R. Abdominal Wall Blocks in Abdominal Surgery: An Update. International Journal of Regional Anaesthesia. JanuaryJune $2021 ; 2: 47-53$.

13. Forero M, Adhikary SD, Lopez H, Tsui C, Chin KJ. The Erector Spinae Plane Block: A Novel Analgesic Technique in Thoracic Neuropathic Pain. Reg Anesth Pain Med. 2016; 41:621-7.

14. Chin KJ, Versyck B, Elsharkawy H, Rojas Gomez MF, Sala-Blanch X, Reina MA. Anatomical basis of fascial plane blocks. Reg Anesth Pain Med. 2021; 46:581-99.

15. Lonnqvist PA, Karmakar MK, Richardson J, Moriggl B. Daring discourse: should the ESP block be renamed RIP II block? Reg Anesth Pain Med. 2021; 46:57-60.

How to cite this article: Gopal TVS | Ultrasound and Modern Regional Anaesthesia | International Journal of Regional Anaesthesia | July-December 2021; 2(2): 100-101. 